\title{
Against the pragmatic justification for realism in economic methodology
}

\author{
SIMON DEICHSEL \\ University of Bremen
}

\begin{abstract}
In recent times, realism in economic methodology has increasingly gained importance. Uskali Mäki and Tony Lawson are the best-known realists within the discipline and even though their approaches are fundamentally different, both provide (among others) pragmatic defences of realism by claiming anti-realism to be the reason for the low quality of (some) economic models. My paper will show that a pragmatic defence of realism is untenable and furthermore, I will show that for both Mäki's and Lawson's normative ideas there is no need for realism.
\end{abstract}

Keywords: realism, anti-realism, Uskali Mäki, Tony Lawson, pragmatism

JEL Classification: B40, B41, B49

Every discussion of realist philosophy of science must begin by distinguishing the different forms of realism and by declaring what is exactly at issue. The following list provides an overview of different realist positions in philosophy of science, in ascending order, by the strength of claims being made:

1. Ontological realism: This is the most modest realist claim and merely entails the belief in the theory-independent existence of an external reality.

2. Weak epistemic realism: Scientific theories refer to an external reality and may be right in their claims about it, i.e. they are capable of being true or false. This includes the semantic thesis that theories are true if and only if they correctly refer to an external reality.

AUTHOR's NoTE: I wish to thank the editors of EJPE, Manfred Stöckler, Dagmar Borchers, Andreas Pyka, the members of the PhD-seminar of the Institute of Philosophy in Bremen, the audience of my talk at GAP.7, and two anonymous referees for their very helpful comments. 
3. Scientific realism/strong epistemic realism: Well-confirmed scientific theories refer to an external reality and are basically right in their claims about it. ${ }^{1}$

Both weak and strong epistemic realism are deeply connected with a correspondence theory of truth, because their central point is to make claims about the properties of an external reality. If those realists would rely on a coherence- or consensus-theory of truth, this would directly beg the question. In this paper, I take anti-realism as the thesis that we should suspend judgement on the truth and truth-worthiness of our theories or avoid talking about the truth of theories altogether in order to minimize the confusions that surround this concept. ${ }^{2}$ I analyse the pragmatic aspects of the justifications for realism that one might interpret from the distinctive projects of two prominent realists in economic methodology: Uskali Mäki and Tony Lawson. I argue against these pragmatic aspects and try to show why an anti-realist perspective is preferable.

\section{USKALI MÄKI'S REALISM}

Uskali Mäki's overall strategy consists in developing a disciplinesensitive brand of realism that is tailored to analysing many of the traditional problems in economic methodology. His approach can be described as "bottom-up", which means that he tries not to invoke external philosophical concepts for criticising economics, but attempts to first understand what economists are doing before seeking a realist interpretation for it. Mäki's justification for taking a realist position is pragmatic insofar as he fears that giving up realism "would result in the worst kind of complacency" (Mäki 2002, 102). I call this a pragmatic justification, because it focuses on the good consequences that an adoption of realism would have.

Mäki believes realism can offer arguments against the well-known defence of abstract economic reasoning that jumps from the premise that all models are false anyway to the claim that all criticism against the falsehood of economic models is to be rejected (Mäki 2009a). In a definition of realism that Mäki gives, it becomes clear that his

\footnotetext{
1 This list is not meant to be exhaustive. The qualification that theories are only "basically" right allows for structural realism as well. See Worrall 1989, for the locus classicus.

${ }^{2}$ Note that I do not claim that no theory can be possibly true-there may well be theories that are true (even if just by chance) but we should avoid talking about the truth of theories.
} 
realism is based on a correspondence theory of truth, as he argues that good science pursues theories that are true by corresponding to reality ("the objective structure"):

[...] theories and models are true or false by virtue of the ways of that objective structure-not by virtue of whether evidence supports them or whether we are otherwise persuaded to believe in them, for example. Finally, good science pursues theories that are true, while being prepared for the possibility of error (Mäki 2009a, 74).

Mäki's realism allows him to discuss whether economic models resemble the real world. He distinguishes between models, whose internal analysis is for economists a complete substitute for analysing the real world to other models that are a useful surrogate for doing this (Mäki 2009a). While the terminology of substitutes and surrogates may be confusing, the claim that some economists are getting lost in abstract formal analysis is quite plausible.

A main point of Mäki's work consists in demonstrating that highly idealised economic models can relate to reality so that their analysis can be a useful surrogate for conducting direct empirical research. Mäki states that economists "can be philosophical realists about their models even though these describe imaginary situations" (2009a, 79). Indeed, he turns the above argument against the relevance of falsehood upside down: even if all models are necessarily false in their details, we can believe them to be essentially true because the idealisations are strategic and necessary falsehoods, which aim at isolating the true core of a model. Referring to Hausman (1992), Mäki takes the high degree of theoretical isolation in economics to be the reason why it is an "inexact and separate" science. Mäki compares his approach to Nancy Cartwright's (1983) point that economics lies because the world is messy and the models are cleaned of disturbing factors, but in contrast to Cartwright, he sees the chance for models to be true of basic causal mechanisms, even if the messy world seems to contradict them (Mäki 2009a, 81). Yet it is undeniable that some assumptions in economics are merely introduced for tractability reasons and not because they isolate central factors (take, e.g., the assumption of perfect knowledge, the ignorance of transaction costs, or constant returns to scale). Mäki acknowledges this detail and asserts that relaxing such assumptions (and not the ones required for theoretical isolation) as a major driving 
force of economics becoming more realistic, in the right sense (Mäki 2009a, 83-85).

It should be recognized that Mäki borrows an important argument in favour of realism from Lionel Robbins (1945): the view that economics does not create new "unobservables" but deals with entities that are close to commonsense (which he calls "commonsensibles"), such as firms, households, and prices. These entities have a certain amount of "reality" because we deal with them in our daily life (in contrast to physical entities like electrons or quarks). Even if the commonsensibles economic theory deals with are highly idealised, the idealisation is "strongly constrained by economists' commonsense intuitions" (Mäki 2009a, 88). This leads to the rejection of models that contradict commonsense, making the differing commonsense convictions of economists a highly crucial point in theory choice. But if we accept that the basic entities of a certain economic model are based on commonsense notions, it becomes clear why the existence of the basic entities is not the main point of a realistic position in economic methodology. Instead, the main point is about the reality of the causal mechanisms postulated by economic models.

In the end, Mäki admits that it is quite impossible to know whether his philosophical meta-theory of realism is true, and even worse, when we agree that economic models may be false (due to epistemic and institutional factors), we are forced to admit that the meta-theory may be false for the very same reasons. This leads Mäki to adopt fallibilism as the super rule (Mäki 2009a).

In a recent text called "Some non-reasons for non-realism about economics", Mäki rejects several premises that seem to support an antirealistic interpretation of economics. Here is a short summary of his counter-arguments (Mäki 2002, 92, et seqq.): ${ }^{3}$

Thesis 1: "Economics postulates unobservables, therefore it is better interpreted by non-realism". Mäki responds that this happens in every science and is no reason for non-realism, especially because many of the unobservables in economics are "commonsensibles" as explained above.

Thesis 2: "Economics is based on false assumptions; this is an argument for interpreting it by non-realism". Mäki responds again that this is true for all sciences in a strict sense, so it is no reason for

\footnotetext{
${ }^{3}$ See Hodge 2008, for a discussion.
} 
non-realism. The relevant question is, whether the false assumptions help to isolate parts of reality or not.

Thesis 3: "Economics is not predictively successful, so the basic premise for the no-miracle argument is missing, which is an argument for non-realism". Mäki responds, as explained above, that we have more direct access to economic phenomena by our commonsense, so believing in the reality of basic economic premises does not need to be justified by the no-miracles argument. Besides that, he claims, taking into account the complex nature of economic systems, it would be rather a miracle if economics was indeed predictively successful.

Thesis 4: "When accepting a theory, economists are persuaded (and not rationally convinced!) by many social factors, which is an argument for non-realism". Heavily abbreviated, Mäki responds by arguing that persuasion is completely orthogonal but not antagonist to truth, and therefore the argument is not directed against realism. Even if the influence of "irrational" factors is strong, the resulting theories can still be true.

These arguments show how anti-realism should not be justified, according to Mäki. They also show that his justification of realism often consists in attacks against anti-realism combined with an appeal to realist intuitions. However, as mentioned above, it should be noted that Mäki also provides a pragmatic justification for his realism when he expresses the fear that giving up realism could lead to justify anything in economics, even if it was only "a game of just playing with fictions" (Mäki 2002, 102). Obviously Mäki believes in the good methodological consequences of realism and, again, this is what I call a pragmatic justification. While Mäki is doubtful whether a strong epistemic realism can be achieved, he clearly sets this as an aim (Mäki 2002).

Below I will consider whether Mäki can live up to the task of improving economics by means of his realism. Before this, in the next section, I will present the other key realist position in contemporary economic methodology, Lawson's critical realism.

\section{TONY LAWSON'S REALISM}

Tony Lawson's critical realism differs fundamentally from Mäki's realism. Where Mäki is generally neutral or even affirmative concerning mainstream economic theory, Lawson decidedly wants to use realism as a tool for criticising current mainstream economics. Lawson starts with 
the premise that mainstream economics is in a state of disarray, because it focuses too much on formalised deductive modelling and does not deal with real world issues (Lawson 2001). He locates the fundamental error of mainstream economics in its anti-realist methodology which sees truth as an irrelevant criterion for theory evaluation. His basic argument is that anti-realism leads economists to ignore the central problem of their field by rendering the lack of realisticness of theories unproblematic by definition. According to Lawson, the anti-realist is in a desperate situation, if theories are not successful at predicting empirical data. In this case, the anti-realist usually recommends trying harder, digging deeper, and searching for regularities at a more disaggregated level-realism is the recommended way out of this problem.

Lawson states that in some sense nearly everybody is a realist because even methodological anti-realists often accept ontological realism. For this reason he defines his blend of realism by its "sustained concern with ontology" (Lawson 2001, 168). By this focus on ontology, Lawson hopes to learn something about the nature of social phenomena, which he thinks will enable him to give better methodological advice to economists than anti-realists can. This is a pragmatic defence of realism as it concentrates on the positive consequences of adopting critical realism. Indeed, it is much more explicitly pragmatic than the defence Mäki gives, because Lawson's project is much more normative. In his most recent book Reorienting economics, Lawson even suggests that all heterodox traditions are best understood by looking at the "social ontology" they presuppose (Lawson 2004).

Lawson's most important critical point concerns deductivism. He states that the formalistic models of mainstream economics necessarily rest on a deductivist mode of explanation, even if that fact may be concealed by the usage of stochastic variables or non-linear equations. According to Lawson, the fundamental problem of deductive reasoning is its dependence on closed systems that are characterised by stable observable event regularities. However, Lawson suggests, "that the social realm is everywhere open, that scientifically interesting event regularities rarely, if ever, occur" (Lawson 2001, 170). This makes deduction of future events or using theories as tools for prediction not only difficult, but inherently wrong. Lawson argues that deductivism in economics needs an ontology

of structures, powers, mechanisms and tendencies, etc., that are irreducible to, but which underpin the actual course of events and 
states of affairs. Once this ontology is established it supports a conception of science as moving from phenomena at one level to its conditions or causes at a different, deeper, one (Lawson 2001, 172).

Lawson states that deductivists (including predictive-anti-realists) cannot discuss these matters and are therefore unable to explain why science is in fact successfully applied to open systems where event regularities do not hold (Lawson 2001). ${ }^{4}$

In Lawson's view, economic laws should not be made to represent observable event regularities, but rather the underlying workings of mechanisms and tendencies. He argues that his realist perspective should be accepted due to its greater explanatory power concerning the question as to how it is possible that results which hold in closed systems can often be meaningfully transferred to open systems, even if the predicted event regularities do not hold there (Lawson 2001).

His studies in "social ontology" lead Lawson to claim "that economics ought really to move in a different direction entirely, to develop ways of uncovering causal mechanisms in a seemingly quintessentially open, as well as intrinsically dynamic, and highly internally-related, social reality" (Lawson 2001, 175). The described social reality has not the same ontological independence of human thought as natural reality, because it is a human construct and hence depends directly on human thinking. Lawson rejects the view that all causal forces in the social realm are reducible to individuals, because the socio-economic structures exist prior to individual action (Boylan and O'Gorman 1995).

Even if Lawson's social ontology is supposed to reveal "deeper structures" and "essential features" it does not include the claim of ultimate knowledge about these matters and Lawson admits its findings are fallible (Lawson 2001). If one accepts Lawson's ontological claims, a methodology that takes individual reactions to changes in relative prices as its basis is ill-conceived, because it neglects the freedom of human choice and the power of social structures systematically. Orthodox economic theorising therefore often employs convenient fictions that state very general and tractable connections between variables, instead of looking after the real and essential forces (Boylan and O'Gorman 1995).

\footnotetext{
${ }^{4}$ Note the similarities between Lawson's view and Hausman's notion of tendency-laws.
} 
Adopting his methodological views will lead, according to Lawson, to an economics that is a much more complicated and messy affair than the current mainstream. In this context, the best one can hope for is a kind of interpretative explanation (i.e., not prediction) of so-called demiregularities, a term that is essentially equivalent to Kaldor's "stylised facts" (Lawson 2003). In short, Lawson states that economics should be concerned with the essential features of economic systems and his critical realist methodology is made for knowing what they are.

\section{CRITICAL DISCUSSION}

We have now seen in some detail how the two main protagonists of realism defend their philosophical thesis. I will argue that "truth" is almost always replaceable by other terms that are ontologically more parsimonious (such as empirical adequacy ${ }^{5}$ or fit with the totality of current knowledge ${ }^{6}$ ) and may nonetheless fulfil the intentions the respective author had. While I accept many of the conclusions that Mäki draws (and some of Lawson's), I cast doubt on whether realism is necessary for justifying these conclusions. The next sections will elaborate on these doubts.

\section{Discussion of general justifications for realism}

The philosophical dispute about realism is of course not easily settled. I will first sketch some general arguments against realism, before I deal specifically with Mäki's and Lawson's arguments.

Let's start with the famous "no-miracle" argument for scientific realism. In its most basic version it simply states that realism is the "only philosophy that doesn't make the success of science a miracle" (Putnam 1979, 73). It states that the success of scientific theories can be explained by claiming that these theories capture elements of an external reality. It is true that anti-realism cannot offer such an explanation, but the crucial question is, whether the realist move is an explanation at all. Often, it seems that the realist's arguments are begging the question of the anti-realists, and vice versa. I think this is the case for the "no-miracle" argument as well. The anti-realist would claim that we are not justified in explaining the success of science by its

\footnotetext{
${ }^{5}$ See van Fraassen 1980, for the locus classicus of a defence for this criterion.

${ }^{6}$ In the sense of Quine and Ullian 1970.
} 
truth $^{7}$ because theories could possibly be successful without being true, due to empirical underdetermination. ${ }^{8}$ In short, scientists often accept those theories that work well and that is all there is to say. Accepting truth (in the sense of correspondence) as the best explanation for their success means to go beyond the borders of what we can legitimately infer. From this view, the suggestion that truth explains the success of theories is no explanation at all-it is rather an illegitimate ad-hoc statement. We could equally argue that the existence of God is the best explanation why our theories work, but anti-realists are convinced we should not do that on the same grounds why we should not "explain" success by a correspondence to an independent reality. In both cases, the explanation is based on uncertain ontological claims. But we can know whether a theory is helpful for solving our problems because that is a completely subjective judgement which does not involve an ontological claim. ${ }^{9}$

A stronger argument in favour of anti-realism is the fact that even inconsistent theories can "work" which shows that taking truth as an explanation for success is problematic because the truth can hardly be inconsistent (da Costa and French 2002).

Once we talk about the acceptance of the "inference to the best explanation" the quarrel between realists and anti-realists gets more complicated. In her daily work, the anti-realist may accept and use some theories because she holds them to be the best explanation for a phenomenon under scrutiny. For example, the anti-realist may accept increased demand for oil as the best explanation for a rising oil-price. Now the realist can ask why the anti-realist stops short of accepting realism as the best explanation for the success of theories and hence does not give up his anti-realist position. At this point, it becomes clear why the "no-miracle" argument is question-begging and cannot settle the argument between realists and anti-realists: both may be willing to accept best explanations, but the anti-realist never asserts the truth of the explanations she accepts and so will not accept truth as the best explanation for success. Furthermore, the argument that scientific theories can fail does not refute anti-realism. It merely supports what

\footnotetext{
${ }^{7}$ Keep in mind that I assume that realism is committed to a correspondence theory of truth by definition.

${ }^{8}$ Underdetermination claims that two theories can both be empirically adequate while making different claims about reality.

${ }^{9}$ Larry Laudan (1996) provides details on the problem-solving approach to scientific progress.
} 
I have dubbed "ontological realism", that is, the view that there is an external reality, which can be incompatible with our theories. However, it does not show that those theories which are compatible with the external reality are such because they are "true" or "realistic".

The arguments given in this section show at minimum, that the traditional justifications for realism cannot settle the dispute. Let us see if Mäki and Lawson have something to add.

\section{Against Mäki's pragmatic justification for realism}

Before criticising some of Mäki's arguments in support of realism, I should state that I accept many of his arguments and generally share his point of view-except for its realist branding. I welcome his bottom-up approach, I accept his distinction between "realism" and "realisticness", and I accept his point that many assumptions in economic models serve the tractability of models rather than their epistemic value. His arguments concerning these points are careful and convincing which is why they do not have to be repeated here.

The main point against Mäki's usage of the term "realism" is that it is merely a brand-name. Mäki explicitly admits that many other methodologists contribute to the realist project, even if they do not do it "under the banner of realism" (Mäki 2007, 438). This, of course, raises the question if the term "realism" as Mäki uses it is informative at all. The main problem when trying to refute Mäki's realism is the lack of a real defence that could be attacked. His lack of the defence is evident in his attempt to defend realism against McCloskey's postmodernist (McCloskey 1985) charges in opposition to the very notion of an external truth:

In my alternative realist account of rhetoric, the world and truths about the world are not dependent on persuasion amongst economists and their audiences. I reject the presumption that the occurrence of rhetorical persuasion alone rules out the possibility of attaining and communicating persuasion-independent truths about economic reality (Mäki 2009a, 91).

Instead of defending realism with arguments Mäki admits beginning with the intuitions of a realist Mäki (2009a). He then proceeds by showing how much of the economics literature can be rendered intelligible by his realist interpretation. I am the last to doubt that Mäki is immensely successful in this, but I doubt whether this really is a 
justification for realism instead of preaching to the already converted (Schliesser 2010). Mäki's work does show that realism offers a good way of talking about problems of economic methodology. However this is not enough for refuting anti-realism. Now, if Mäki wants to defend his brand of realism pragmatically, he needs to show how his version of realism would lead to an improvement of economic research and which standards it would specifically employ apart from standards that are compatible with anti-realism such as problem-solving capability or empirical adequacy.

The lack of this discussion in Mäki's work and, as I would say, the impossibility to show specifically how realism would change economic research, makes a pragmatic justification for realism difficult to provide. Mäki, at best, gives reasons which show that it is sometimes just natural to assume an external world and economic models relating to it and the realist can talk about unrealistic models that do or do not capture features of the world. Here, however, the anti-realist would talk about making assumptions that diverge from our current believes about the world, but nonetheless make successful (structural) predictions and by this, offer plausible explanations.

Mäki uses his realist rhetoric to argue against mere derivational unification (deriving more outcomes from the same set of premises) and in favour of ontological unification-establishing more "ontic unities" between phenomena, i.e., showing that they are of the same kind (Mäki 2009a). This sounds convincing, but is it really a normative guideline that differs substantially from what an anti-realist would advocate? As long as realism does not provide a unique standard to distinguish the two modes of unification, we are left with commonsense arguments that are not opposed to anti-realist positions.

This, of course, undermines any normative thrust for realism as we are still left with anti-realism-compatible standards such as empirical adequacy plus some pragmatic values like simplicity, fertility, modesty, and conservatism. Mäki often speaks about the way the world works (www) constraint (Mäki 2009b), which refers to economists convictions about real causal connections in contrast to their model results. But this is hardly a constraint at all if we cannot know when it is met. In another recent paper Mäki seems to mean that the "www constraint" is nothing more than the idiosyncratic ontological intuitions of economists (Mäki 2009a). This is of course unproblematic for the anti-realist, because it is 
only a consistency criterion and as such is a far cry from making ontological claims in a stronger sense.

As I said, Mäki pragmatically justifies his realism as a powerful instrument of criticism for economic models (Mäki 2002). To me, the issue seems the other way round: realism is the less critical methodology when compared to anti-realism because it allows talking about truth where anti-realism suspends judgement on this matter. Mäki's recommendation for developing useful surrogate models instead of getting lost in internal formal analysis or his suggestion to check models against commonsense intuitions can be kept without subscribing to realism of any form.

\section{Against Lawson's pragmatic justification for realism}

Now let us see how Tony Lawson's critical realism scores against critical scrutiny. Where Mäki's work is rather neutral towards economic methodology, Lawson intends to overthrow economic orthodoxy. If one is inclined to accept the methodology of mainstream economics as it is and therefore does not share Lawson's view that the search for observable event regularities fundamentally contradicts the ontology that underlies social processes, there is little reason to follow his demand for more realism. And, even if one disagrees with much that is going on in mainstream economics there is no need to accept Lawson's realist critique. It is important here to keep in mind that Lawson proposes a normative methodological realism. In his view, economics should deal with the real forces that move societies and these cannot be modelled in the deductivist style. As Jack Vromen (2004) notes, where mainstream economists cherish elegance, simplicity, parsimony, tractability, unifying power, and the like, Lawson wants to assign greater weight to other epistemic virtues such as truth, or realisticness, credibility, and plausibility.

But is Lawson justified in demanding this? There are at least three reasons why I disagree with his position: first, we cannot know what the "real forces" are; second, his proposal can be turned against any form of idealisation; and third, it is doubtful whether mainstream economics is well characterised by Lawson's interpretation of the term "deductivism" at all.

I will not deal in much detail with the first point here, as I laid it out already in quite some detail in my discussion of Mäki's realism. It is important to note that this point is even more crucial for Lawson 
because of his strongly normative orientation. Lawson urges economists to deal with the true and essential powers, but fails to show how anyone can have such knowledge apart from criteria that are acceptable for antirealists as well. Lawson argues in the typical question-begging way that characterises the debate between realists and anti-realists; he accuses anti-realism of ignoring the central problem of realisticness (Lawson 2001). But a main conviction of anti-realism is to reject the idea of talking about realisticness (in the realist's sense), and therefore this is not an argument against anti-realism at all.

Second, let me grant that Lawson's continuous demand to search for the real structures in inherently open social systems may lead to a more realistic and detailed description, but taken seriously it is headed against many forms of abstract theorising and idealisations. There are many theories that would have to be abolished right away if Lawson's normative realism was uniformly accepted. Just think of formal decision theory, game theory, any theory employing folk psychological reasoning, any form of hypothetical contractarianism and even political liberalism, because they are all admittedly based on unrealistic assumptions.

It is questionable, whether looking for the real essential powers that drive human behaviour will soon lead to theories of any use for economic problems. It seems more likely that such a procedure will setoff a quest into the mysteries of the human brain and the freedom of the will. Lawson does not promote this, but takes his favourite project called "social ontology" as a starting point. The sustained concern with social ontology is bound to realism by definition in Lawson's project (Lawson 2001). But is Lawson justified in his demand that economics should be reoriented to become a science based on social ontology? This can be denied at two different levels: first, it is not obvious his social ontology gives us a realistic representation of the social world. Surely, the attempt to incorporate our commonsense knowledge about social systems (e.g., the claim that social processes are dynamic and inherently open processes) into the fundament of economic theory will make this fundament more realistic by our commonsense standards. But again, there is no viable criterion to judge in which sense a "reoriented economics" that is based on social ontology approaches or mirrors an external reality except for the notoriously vague commonsense. Or, as Wade Hands puts it, "critical realists [...] offer no unique method [...] that gives us access to those enduring structures" (Hands 2001, 327). Besides that, it is even doubtful if Lawson's ontology that assigns social 
structures an individual-independent existence is indeed more realistic even by commonsense standards.

Second, for the sake of Lawson's argument let us accept that an economics that depicts the inherent dynamics and openness of social systems fits better into the totality of our current beliefs than the mainstream mechanistic picture. This fit is surely not an absurd standard for "realism" in economics. But is it a helpful normative guideline to improve this fit? I have my doubts. Also at the methodological level more realism may not be helpful, because the increased detail of research based on "social ontology" is not likely to be a useful basis for theorising, because the emerging picture is too "messy" for that. While a deterministic picture of humans as rational agents may be false, it can be fruitfully so. To be sure, Lawson would deny this because he thinks the whole project of mainstream economics is on the wrong track. Alas, this fundamental assumption of his work is not carefully argued for. Lawson merely provides a collection of critical voices and adds the claim that mainstream economics is not successful with accommodating the data (Lawson 2001). This is at best only a half-truth: surely economics is very unsuccessful at predicting the next financial crisis or even the growth of the GDP for more than one year. But on the other hand there is a plethora of well-confirmed conditioned predictions of tendencies and progress in their prediction (during non-crisis situations) without the need to refrain from the underlying "deductivist" structure. Therefore, Lawson is not justified in completely rejecting the mainstream research programme. Of course, he is free to start his own project of critical realist economics that is based on social ontology, but as long as there is no agreement about the mainstream being in disarray, so the only escape would seem to consist in changing the goals entirely, and not accepting (even conditioned) prediction as one of them, Lawson will hardly gain many adherents. So even if we accept that Lawson's ontological approach is more realistic, it does not follow that it is pragmatically convincing and should be adopted. ${ }^{10}$

\footnotetext{
${ }^{10}$ This is of course the typical situation with any paradigm shift. Lawson is aware of this and therefore he mainly addresses those who accept that the economic mainstream is in inescapable disarray. Note that Lawson does not intend to use his ontological research for building an alternative economics with it. Rather he wants to support existing heterodox schools by showing that their foundations are ontologically more realistic than those of mainstream economics. His project is essentially about improving heterodox economics by reinterpreting and refining their presupposed ontological commitments. See Lawson 2003, part III.
} 
Now let us turn to the third point, namely the question whether mainstream economics is adequately characterised by Lawson's label "deductivism". As he describes it, deductivism is necessarily committed to a notion that characterises scientific laws as observable event regularities. This is a great misunderstanding. The mathematicaldeductivist style which is admittedly often used in mainstream economics does not commit economists to a "flat" ontology that forbids any talking about underlying structures that causes event regularities to occur. As Vromen (2004) notes, economists try to look for more than just event regularities and are even encouraged to do so by Friedman's (1953) classic methodological manifesto. Despite the common usage of mathematical deductions, mainstream economics aims at uncovering underlying structures of the social world-they do this by devising an axiomatic theory that offers a possible explanation for the observable data. $^{11}$ Instead of calling this method deductivism one is equally justified in calling it abductivism, for abduction is precisely the development of a theory trying to explain the facts. Mainstream economists of course reject the interpretation that they have found and even that they should find true and realistic underlying structures, as Lawson demands.

There is another confusing point about Lawson's sharp distinction between underlying structures and event regularities. If one accepts (as I argued most economists do), that scientific laws are not about the event regularities but rather about the underlying structures that cause them, one can still continue to dig for event regularities by arguing that an underlying structure must somehow show up in the empirical data. This would seem to imply that Lawson is much closer to mainstream methodology that he is willing to admit. One of his main points is the denial of strict event regularities in open systems, which he takes as an argument against deductivist modelling. He prefers "demi-regularities". Now it is hard to believe that mainstream economists would really insist on the strictness of the regularities in question and would reject searching for demi-regularities. Surely Daniel Hausman's (1992) characterisation of economic laws as tendency laws may indicate that the mainstream view is not all that distinct from Lawson's view.

There are many points in mainstream methodology that resemble aspects of Lawson's critical realism, but the realist parts of his methodology do not demonstrate why realism is justified or preferable

\footnotetext{
${ }^{11}$ See Reiss 2004, for a similar view.
} 
to a more modest (anti-realist) methodology. Lawson commits the realist fallacy that assumes higher realisticness (even if seen as descriptive accuracy of the assumptions) should be an end in itself and by this excludes many forms of theorising that are commonly accepted to be useful or successful. This is the main reason why his plea for more realism is pragmatically unconvincing.

\section{CONCLUSIONS}

This paper has covered a lot of ground. Now it is time to step back and draw several conclusions: is realism pragmatically helpful for theory appraisal in economics? It should not surprise the reader that I answer this question negatively. If scientists (in contrast to philosophers) want to assess theories, they almost always want to know how well they work, not why. The on-going battle between realism and anti-realism in traditional epistemology can be separated completely from issues pertaining to theory appraisal. Even if there was a conclusive proof in favour of scientific realism this would still allow for a purely instrumental way of assessing theories, i.e., deciding how well they are suited for solving given problems, since this question can be completely separated from their truth-status. Put slightly differently, if one wants to make normative statements, pragmatic reasons are needed, however, as I tried to show above, it is difficult to defend realism on pragmatic grounds as adopting realism does not lead to normative implications that are unavailable to the anti-realist.

Such weaknesses notwithstanding, it should be clear that this does not imply that there is nothing acceptable in the realist's prescriptions, even if they stem from the wrong reasons. For example, within the assumption debate, the realists carefully distinguish between assumptions that isolate real factors and others that merely serve the tractability of economic theory. A certain type of anti-realism may accept the message that it is important to filter out the crucial, the fundamental or the necessary assumptions of a theory even if it would hesitate to call them real. Such a procedure could be called "anti-realist ontology" as it is a venture into the status of the very fundamentals of economics and by this it would save the lessons from one of the realists' preferred projects, without committing to a version of ontological realism (as defined above).

Another possible form of anti-realism may even agree with Mäki's recommendation of developing useful surrogate models for analysing 
the real world instead of playing with substitutes, but in contrast to Mäki, the anti-realist would not ask whether a model is representing "the real world" but would focus on its ability to shed light on real problems. If the problem to be solved is one of policy-consulting, it should be clear even to the anti-realist that research on the formal aspects of some general equilibrium model can become a dangerous substitute for practically relevant economic research. However if some formal aspects are indeed the problem a scientist wants to deal with, the anti-realist must accept this and cannot urge her to concentrate on surrogate models. A type of anti-realism could indeed accept a kind of "as-if-realism", which accepts many arguments and terminological points, but rejects the interpretation that theories or parts of them are literally true. ${ }^{12}$ With this in mind, the anti-realist could actually talk about more "realistic" assumptions when he uses a coherence theory of justification instead of a correspondence theory of truth. ${ }^{13}$ The debate about realism against anti-realism would then be merely about semantics bearing no pragmatic implications whatsoever. Then, the more realistic assumptions would be the ones that fit better to the totality of our current beliefs..$^{14}$ It is however another main point (that I argued for above), that more realistic assumptions are not always the better ones, but that we should rather look for adequate idealisations for the problem at hand instead of mechanically heading towards more realisticness. If one accepts these arguments, it is difficult to defend realism pragmatically as a critical therapy for economics. There are forms of anti-realism that can do the same, but are far more epistemologically modest concerning the ontological status of theories.

\section{REFERENCES}

Boylan, Thomas A., and Paschal F. O'Gorman. 1995. Beyond rhetoric and realism in economics: towards a reformulation of economic methodology. New York: Routledge.

Carnap, Rudolf. 1950. Empiricism, semantics, and ontology. Revue Internationale de Philosophie, 4 (2): 20-40.

Cartwright, Nancy D. 1983. How the laws of physics lie. Oxford: Oxford University Press.

\footnotetext{
${ }^{12}$ A similar argument is made in Carnap 1950.

${ }^{13}$ The addition of a semantic correspondence theory of truth to a coherence theory of justification is in fact the only feature that clearly distinguishes Mäki's realism from the anti-realism presented here. See Peter 2001.

${ }^{14}$ This suggestion is inspired by Quine and Ullian 1970.
} 
da Costa, Newton, and Steven French. 2002. Inconsistency in science: a partial perspective. In Inconsistency in science, ed. Joke Meheus. Dordrecht (NL): Kluwer Academic Publishers, 105-118.

Hands, D. Wade. 2001. Reflection without rules: economic methodology and contemporary science theory. Cambridge: Cambridge University Press.

Hausman, Daniel M. 1992. The inexact and separate science of economics. Cambridge: Cambridge University Press.

Hodge, Duncan. 2008. Economics, realism and reality: a comparison of Mäki and Lawson. Cambridge Journal of Economics, 32 (2): 163-202.

Laudan, Larry. 1996. Beyond positivism and relativism: theory, method, and evidence. Boulder (CO): Westview Press, Inc.

Lawson, Tony. 2001. Two responses to the failings of modern economics: the instrumentalist and the realist. Review of Population and Social Policy, 10: 155-181.

Lawson, Tony. 2003. Reorienting economics. London: Routledge.

Lawson, Tony. 2004. Reorienting economics: on heterodox economics, themata and the use of mathematics in economics. Journal of Economic Methodology, 11 (3): 329340.

Mäki, Uskali. 2002. Some non-reasons for non-realism about economics. In Fact and fiction in economics: realism, models, and social construction, ed. Uskali Mäki. Cambridge: Cambridge University Press, 90-104.

Mäki, Uskali. 2007. Realism. In The philosophy of economics: an anthology, ed. Daniel M. Hausman. Cambridge: Cambridge University Press, 431-438.

Mäki, Uskali. 2009a. Realistic realism about unrealistic models. In Oxford handbook of the philosophy of economics, eds. Harold Kincaid, and Don Ross. New York: Oxford University Press, 68-98.

Mäki, Uskali. 2009b. Unrealistic assumptions and unnecessary confusions: rereading and rewriting F53 as a realist statement. In The methodology of positive economics: reflections on the Milton Friedman legacy, ed. Uskali Mäki. Cambridge: Cambridge University Press, 90-116.

McCloskey, D. N. 1985. The rhetoric of economics. Brighton: Wheatsheaf Books Ltd.

Peter, Fabienne. 2001. Rhetoric vs realism in economic methodology: a critical assessment of recent contributions. Cambridge Journal of Economics, 25 (5): 571589.

Putnam, Hillary. 1979 [1975]. Mathematics, matter and method. Cambridge: Cambridge University Press.

Quine, Willard V. O., and Joseph S. Ullian. 1970. The web of belief. New York: McGraw-Hill.

Reiss, Julian. 2004. Critical realism and the mainstream. Journal of Economic Methodology, 11 (3): 321-327.

Robbins, Lionel. 1945 [1932]. An essay on the nature and significance of economic science. London: McMillan and Co.

Schliesser, Eric. 2010. Anjan Chakravartty on Brian Ellis, the metaphysics of scientific realism, 2009. It's Only A Theory Blog, Jul/23/2010.

http://itisonlyatheory.blogspot.com/2010/07/anjan-chakravartty-on-brian-ellis.html (accessed August 2010).

van Fraassen, Bas C. 1980. The scientific image. Oxford: Oxford University Press. 
Vromen, Jack. 2004. Conjectural revisionary ontology. Post-Autistic Economics Review, 29: article 4. http://www.paecon.net/PAEReview/issue29/Vromen29.htm (accessed December 2008).

Worrall, John. 1989. Structural realism: the best of both worlds? Dialectica, 43 (1-2): 99124.

Simon Deichsel studied philosophy and economics in Bayreuth and Bologna since 2001. In 2006, he obtained the degree of a Master of Arts (with distinction) with a thesis about model-platonism in economics. His specialisation in philosophy of science and institutional economics set the stage for his $\mathrm{PhD}$ project in philosophy of economics at the University of Bremen where he got a position as research assistant of Prof. Dr. Dagmar Borchers in 2006. Simon was co-supervised by Prof. Dr. Andreas Pyka, and finished his $\mathrm{PhD}$ (with summa cum laude) in October 2009. He currently holds a post-doctoral position at the Institute of Philosophy in Bremen.

Contact e-mail: <simon.deichsel@uni-bremen.de>

Website: <http://www.philosophie.uni-bremen.de> 